\title{
Reconstructing the university: worldwide shifts in academia in the twentieth century
}

David John Frank and Jay Gabler, 2006

Palo Alto, Stanford University Press

$\$ 50$ (hbk); $\$ 19.95$ (pbk), 272 pp.

ISBN 080475375X

Reading this book was something of a rollercoaster ride for me. Its title generated foreboding of dense, arcane, postmodern ruminations. This proved unjustified. Indeed, my gloom was quickly dispelled by the realization that the authors, although using approaches and terminology of postmodernism, also employed good, old-fashioned quantitative data in their analysis. Sadly my elation was frustrated by the discovery that the data were not always apt and that this leads, I think, to some misinterpretation of the (re-)construction of the university.

The fulsome foreword by John W. Meyer, Emeritus Professor of Sociology at Stanford University, sets out a plausible claim for the book. The authors, he says (p. ix), 'make an impressive contribution to the study of the modern (or postmodern) culture and analysis of the university'. They do this by tracing the rise and fall of academic fields in universities around the world, and their assembling 'unique data sets' is 'a major achievement'. Indeed, as the authors' later note, despite the concern of universities to be 'world class institutions' most other studies of them are local (p. 198). So far so good-and there is more promising contention. The assumption that we all know what universities teach and how it has changed is also challenged. Far from seeing the university as 'providing the information and training relevant to the skills needed in the modern economy', the authors see it as 'a central location of the cultural constitution-not the technical skills-of the postmodern society'. It's always encouraging to see a book that challenges the taken-for-granted.

The foreword offers further explanation of this thesis. Why is it, it asks, that higher education has expanded so rapidly, even in developing countries whose economies, for the most part, appear not to need it? In attempting to answer questions like these, the book examines the changing emphases of university teaching and research at several levels. Most broadly, it looks at the 'three main branches of learning' which it sees as humanities, social sciences and natural sciences, and at their division between 'pure' and 'applied'. Next it presents data on the changing composition of each branch of learning's disciplinary field (for example, the development of sociology or economics). Lastly, the changing subject matter within a single discipline (history) is examined. The main data are those on staff numbers from three directories: the Commonwealth universities yearbook, the Index generalis and the World guide to universities. The first is used as the basis for most of the tabulations in the text, as it (and the second) go back to the early decades of the century. The last directory originated in the 1970s. These sources are supplemented by UNESCO data on student enrolments for later periods. Data on courses are from 335 catalogues from 89 countries from 1895 to 1994.

The varying percentages of staff in the different branches and subjects are presented graphically to show the changing balance between them and developments within them. The authors recognize and discuss the limitations of this approach, for example that 
numbers alone do not perfectly represent a university's priorities, and each chapter compares these measures with others to 'test the robustness and validity' of the findings (p. 83). Despite the limitations, theirs is a novel and practical approach-and welcome in that this is a quantitative indicator available on a wide basis.

The data show that 'the university's teaching and research priorities changed profoundly over the twentieth century' and that this 'fundamentally' altered the 'makeup of university knowledge' (p. 47). The social sciences have emerged as a major branch of knowledge, mainly at the cost of the humanities, whose staff representation (in Commonwealth universities) dropped by about 40\% between 1915-1935 and 1976-1995 (p. 65). The natural sciences' share declined, though less (12\%). There has been a general shift from pure to applied, most evident in the natural sciences. From the figures given, this is rather harder to elucidate in the humanities and social sciences, since one has to interpret differential growth of percentage shares. Within the natural sciences, astronomy's share declined most, geology least. In social sciences, sociology gained most, psychology least (both 'pure' subjects according to the classification of the book, and it was not clear from my reading of the text how this is compatible with the earlier finding of the drift to the applied). In humanities it is classics, philosophy and theology whose share declined most, history and non-western languages and literature least. Finally, within the single case of history, the shifts have been from the study of the more ancient, colonial and western towards the contemporary, international, New World and African.

The book, however, is not just about data. The discussion in which the data are employed is based on a number of assumptions about the relationship between the numbers, university knowledge and reality. The core argument is that 'changes in the assumed nature of reality alter the raw materials of university studies' (p. 17) (which can be measured by the data used). Thus, shifts in the emphasis of university studies 'follow from revisions in globally institutionalized models of reality'. The global-institutional framework is constructed from 'the most fundamental assumptions about reality's origins (cosmology) and being (ontology)' (p. 17). These take priority over more national or local frames. Global institutions, the authors assert, are 'built into the cultural scripts and organizational rules of society'. Democracy, mass education and environmental protection are offered as examples. So the model the authors use (tabulated in more detail on p. 20) is causal, essentially sequential (though interactive because subsequent changes feed back):

What do the authors conclude from this analysis? 'What is striking at the world level', they claim, 'is how similar university emphases appear and how standard are their compositions' (p. 199). Even those claiming difference ('unique comprehensive university') are much the same as the rest. This is an interesting piece of empirical evidence of the 'institutional isomorphism' claimed (with little empirical support) by DiMaggio and Powell (1983). For the authors, it confirms the assumption that university knowledge 'is an edifice resting on' the global-institutional framework - 'the assumed nature of reality' (ibid.). Well, it may be, but are these data adequate to test this? Are other explanations possible? None is considered, and the thesis might be seen as what Popper (1963, p. 255) calls 'pseudo-scientific' or, more kindly, 'metaphysical', in that almost any empirical outcome is compatible with it. 


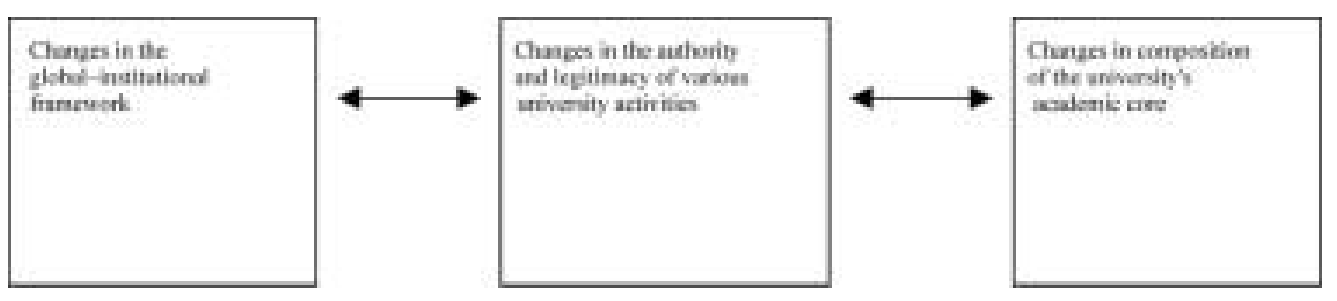

Figure I. Causal model of university construction (simplified version)

So here begins some of my final disappointment. There is this epistemological worry. But there is another concern, about the nature of the data base and the institutions it contains. For, in the second half of the twentieth century, higher education in many countries was transformed by the emergence of non-university institutions (for example, the polytechnics in Britain, Fachhochschulen in Germany) which altered the nature of academic subjects (see OECD, 199I; Pratt, 1997). Not least they established at degree level subjects that had not hitherto been regarded as fit for this arena. Most of these institutions were not admitted to the hallowed Association of Commonwealth Universities (or its equivalents), though since the 1990s, the polytechnics have acquired the title of university-and admission to the Association. This presents a serious methodological problem, not addressed in the book. Leaving these institutions out distorts this bit of 'reality'; higher education may be more aligned to economic skills than this study shows. It is possible to restrict the study to institutions with the title 'university', but the university no longer represents higher education. Moreover, the recent move in many countries (for example UK, Australia) to award this title to these other institutions means that the world 'university' picture after the 1990s would be rather different from that shown in the book. So, after all the promising empiricism and considerable effort, we do not yet have a clear picture of the reconstruction of the university in the twentieth century. It is apparent that it has changed: it is evident that there is a method for assessing this, but how far and why remains frustratingly and considerably uncertain.

\section{References}

OECD (I99I) Alternatives to universities (Paris, OECD).

Popper, K. R. (1963) Conjectures and refutations (London, Routledge).

Pratt, J. (1997) The polytechnic experiment 1965-1992 (Buckingham, Open University Press).

DiMaggio, P. J. \& Powell, W. W. (1983) The iron cage revisited: institutional isomorphism and collective rationality in organizational fields, American Sociological Review, 48, 147-160.

John Pratt, University of East London, UK

(C) 2007, John Pratt 